\title{
NOTE ON GESOMYRMEX
}

\section{By William MORTON WhEELER}

Since the manuscript of my paper on the interesting, Javanese ant, Gesomyrmex kalshoveni, was sent to the printer, Dr. Kalshoven has kindly sent me the remainder of the colony which contained the type specimens, together with a note on the precise situation of the nest. He writes: "The new Gesomyrmex was found in a branch of an Artocarpus elastica ("bendo") in a stand of various deciduous trees-relics of the old natural mixed forest-amidst the teak-forests of Semarang." This statement confirms my supposition in regard to the habits of Gesomyrmex, which evidently lives much like many twig-or branch-inhabiting Camponoti of the subgenera Myrmentoma, Colobopsis, Pseudocolobopsis, Hypercolobopsis, Myrmocladœeus and Myrmobrachys. That the specimens collected by Dr. Kalshoven were living in a piece of primitive forest is of some interest in connection with the fact that the extant species of Gesomyrmex are sporadic survivors, or relicts of an ancient ant-fauna of much wider distribution during the Oligocene Tertiary.

The second lot of specimens from Dr. Kalshoven comprises in addition to 13 workers (one maxima, five mediæ and seven minimæ), which show the same range of polymorphism as described and figured for the first lot, also one male semipupa and two female pupæ. The male semipupa reveals nothing new, but the two female pupæ are interesting. They are approaching maturity since their eyes and mandibular teeth show the beginnings of pigmentation. Both are naked, i.e. not enclosed in cocoons, and measure about $10 \mathrm{~mm}$. They closely resemble the female of G. luzonensis Wheeler from the Philippines, but have distinctly smaller eyes and a much shorter petiole, with less

1See Psyche, vol. 36, p. 1 (1929) 
rounded and more anteroposteriorly compressed node. The antennæ are 10-jointed as in luzonensis, with the funicular joints 3-8 broader than long. The thorax seems to be stouter and shorter than in the species from the Philippines, but the integument is still so soft, that I can infer nothing in regard to the adult proportions of its various sclerites.

\section{A FLIGHT OF PIERIS MONUSTE}

I was much interested in the account by Dr. E. D. Ball and W. E. Stone of "A puzzling Butterfly Migration" (Science, vol. 68, p. 110, 1928). It reminds me of a migration which occured while I was living at St. Augustine, Florida. In June, 1881, there was a northward flight of Pieris monuste lasting for three days. On the first and second days it was a marvelous sight like a snowstorm with large flakes obscuring the view. On the second day a New York schooner ("Nellie Grant") came in. I knew the captain quite well and asked him when he first saw the flight and he said_- "Yesterday afternoon about ten miles off shore." It was the first and only flight I saw during the eight years I lived in Florida, and was noticed at the time as far north as Charleston, S.C. Many asked me the cause of this great flight. I attributed it to a search of the insect for more food plants. There are many cruciferous plants along the sea-coast that are often destroyed by the larvæ. The first brood having devoured all the food plants of the species along the more southern part of the Florida coast, the second brood was compelled to migrate, and in this case it was northward.

This flight was recorded in the American Naturalist, Vol. 15, p. 577, 1881. The report was from Bluffton, near Beaufort, S.C., and occurred June 1 and 2. They were flying "East or northeast." As they were apparently following the coast, this would naturally be the direction they would be flying east of Savannah.

C. W. Johnson. 

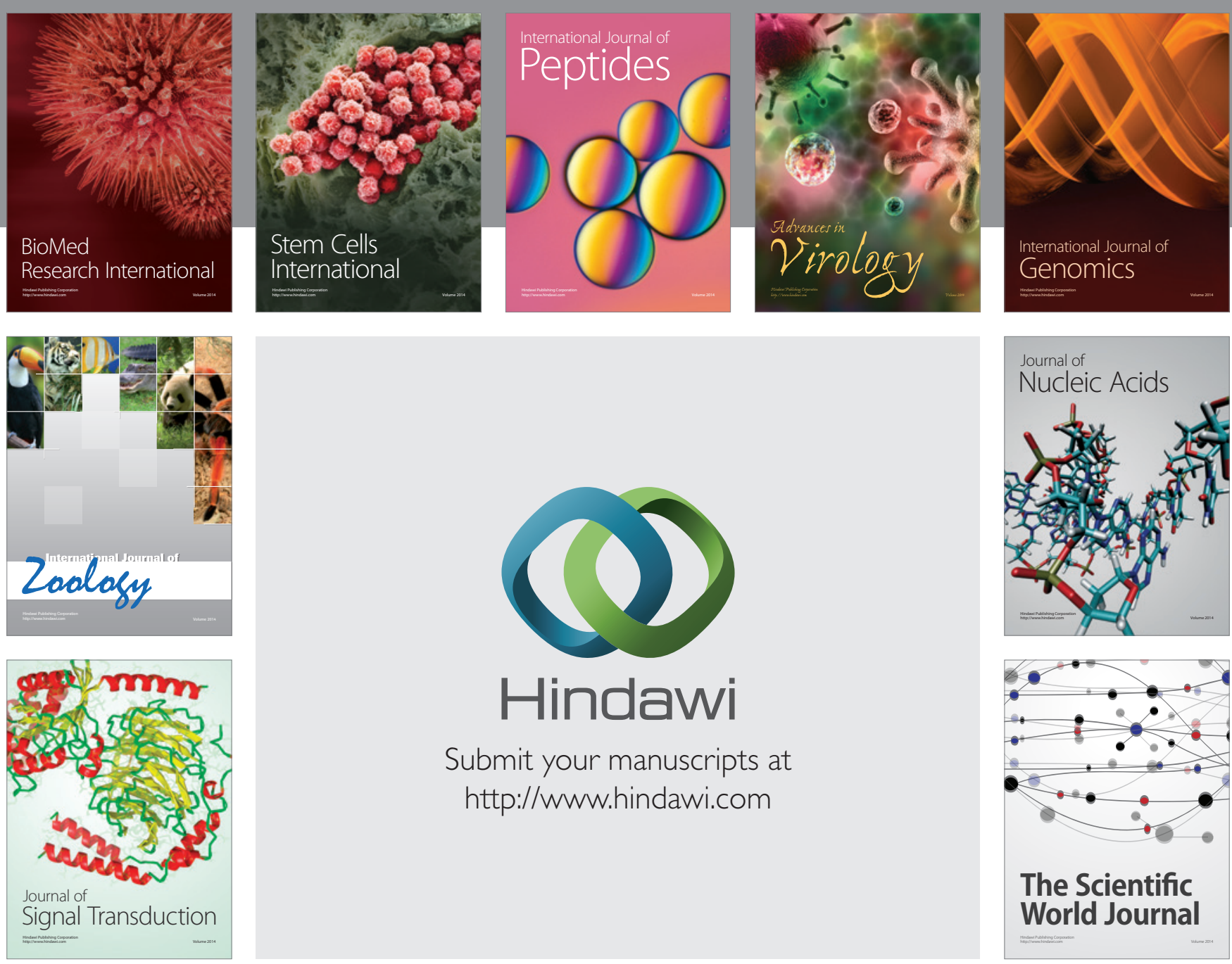

Submit your manuscripts at

http://www.hindawi.com
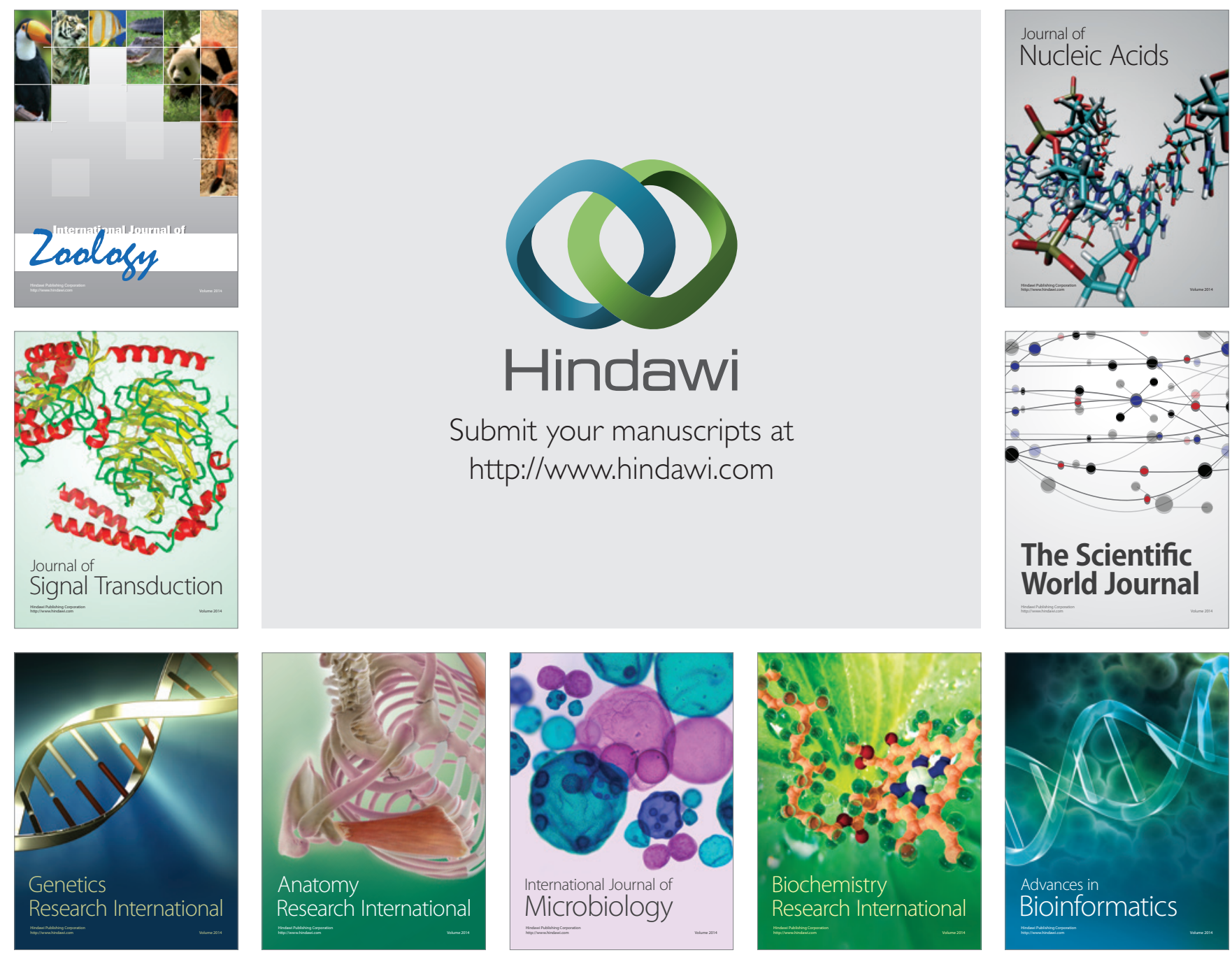

The Scientific World Journal
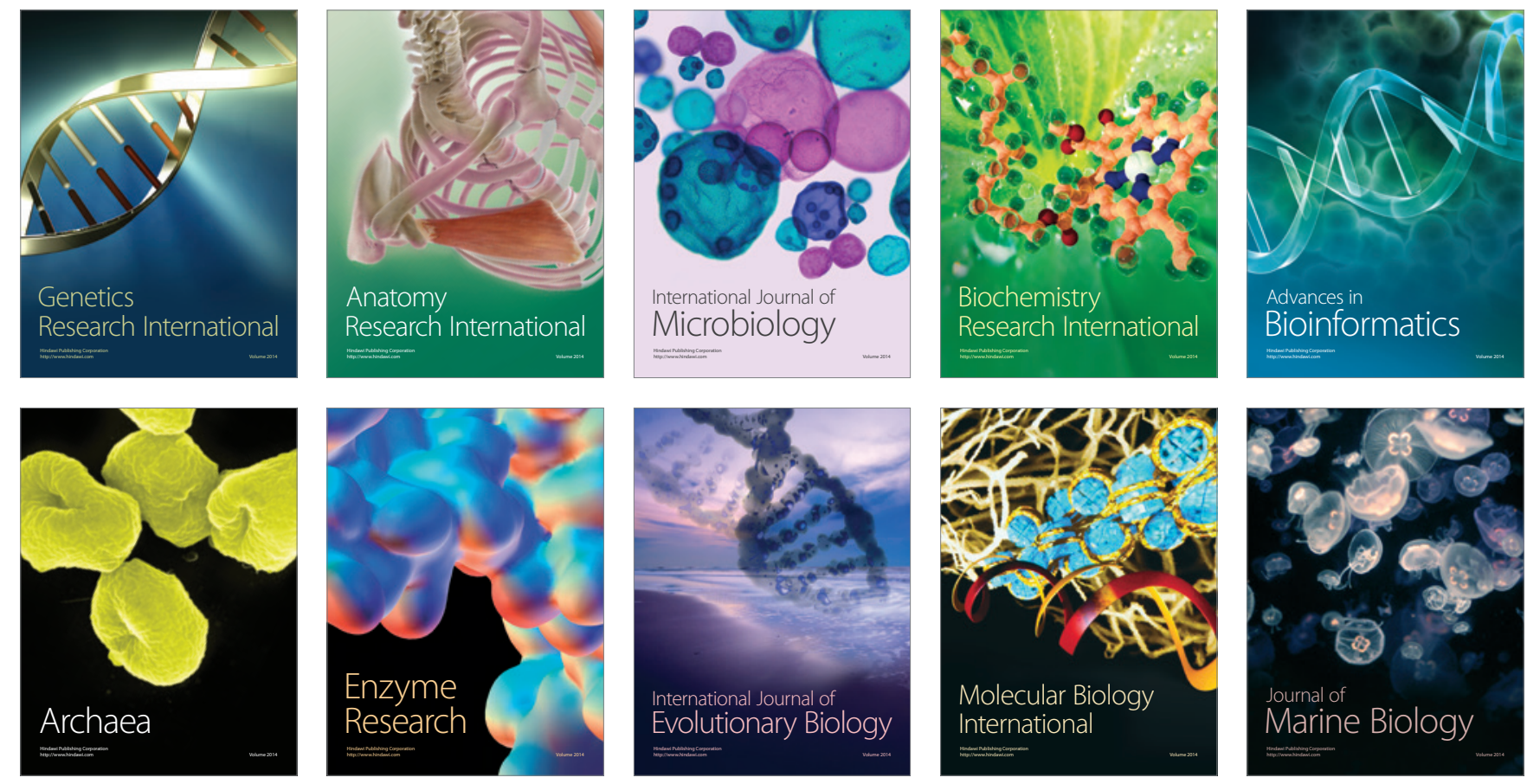